\title{
The Mediterranean Diet Replaced By the Fast-Food Diet: An Observational Study in Pavia, Northern Italy
}

\author{
Giovanna Turconi' ${ }^{*}$, Stefania Moro² ${ }^{\text {, Eleonora Porzio }}{ }^{2}$, Lidia Testa ${ }^{1}$, Miriam Rossi² $^{2}$ Carla \\ Roggi $^{1}$ and Laura Maccarini ${ }^{2}$ \\ ${ }^{1}$ Department of Public Health, Experimental and Forensic Medicine, Unit of Human Nutrition and Dietetics, Italy \\ ${ }^{2}$ Department of Public Health, Experimental and Forensic Medicine, Unit of Hygiene and Preventive Medicine, Italy
}

Received: October 08, 2014; Accepted: March 15, 2015; Published: March 26, 2015

*Corresponding author: Giovanna Turconi, Human Nutrition Researcher, Department of Public Health, Experimental and Forensic Medicine, Unit of Human Nutrition and Dietetics, Faculty of Medicine - University of Pavia - Italy, Via Bassi, 21,Pin: 27100, Tel: 00390382987544 ; Fax: 00390382 987191; E-mail: gturconi@unipv.it

\begin{abstract}
Background: Italian eating habits are being substituted by "globalized" habits: eating fast, nearly in record time, consuming cheaper meals, are associated with modern lifestyle. Indeed, the last few years in Italy have seen a progressive growth in consumption of ready-to-eat foods, pre-cooked food items and partially prepared food products.
\end{abstract}

Objective: To carry out a geographic survey on the counter service establishments in Pavia, create a map of their distribution in the town and investigate their increase compared with past years.

Methods: The location, kind and distribution within the town of counter service establishments were investigated by means of a street survey. Data were collected using a standardized form.

Results: Bar is the most represented category, followed by pizzeria, take-away and self-service and kebab shop in the same extent. The establishments are most widespread in the town Centre area.

Comparing our data with those collected in 2002, the percentage of take-away and kebab shops amongst all the establishments increased from $1.6 \%$ to $12.6 \%$.

Conclusions: Continuing nutrition education programs should be planned and supported by alternative dietary proposals comparable both in price and in fast service, but based on dietary habits characterized by healthy foods, typical of the Mediterranean diet.

Keywords: Mediterranean diet; Counter service establishments; Fast-food diet

\section{Introduction}

Italian eating habits are being substituted by "globalized" habits: eating fast, nearly in record time, consuming cheaper meals, are associated with modern lifestyle.

The frantic rhythm of the current working style with its short lunch breaks, and changes in the traditional family model through which the Italian family, as in other Western countries, has been replaced by different situations (lone-parent families, couples with no children and singles, above all), are the factors that underlie this change in dietary habits[1].

The availability of a wide range of prepared foods is a useful aid for people who have neither time nor desire to spend a long time cooking: the last few years in Italy have seen a progressive growth in consumption of ready-to-eat foods, pre-cooked food items and partially prepared food products [2]. Indeed, the amount of time available for lunch is squeezed in amongst other daily work and family engagements [3].

A recent survey reports that, in Italy, approximately 105 million meals are consumed every day, of which $24 \%$ away from home. Only two out of three meals are eaten with family members. Of the 25 million meals consumed outside the home, $67 \%$ are concentrated around lunchtime. The emerging consumption patterns are "lunch on the run" (11\%) and "grabbed lunch" (5\%) [4].

Lunches consumed in less than 10 minutes are $9 \%$ of all lunches consumed outside the home. Fourteen percent of meals eaten out are consumed standing up, and 15\% while seated, but not at a table. Most of them consist of first courses (41\%) with 1 million ready-to-eat first courses consumed each day, mainly in places like bars or snack bars.

Indeed, the new multi-ethnicity of Italian society has caused the increasing distribution of take-away, kebab shops (in 2011, ethnic fast food was put on the National Institute of Statistics (ISTAT) consumer price index basket) and American fast-food [5-7]. These kinds of counter service establishments offer new foods and globalize dietary habits of Italian people.

On the basis of these considerations, the new globalization promotes a negative influence on the Italian cooking tradition and contributes to the decline of the traditional Mediterranean diet in favor of an unhealthy unbalanced diet.

These modifications in the Mediterranean eating behavior 
appear to be associated with a high incidence of overweight and obesity, above all among children, and other diet-related degenerative diseases [8-15].

The aim of the present study was to carry out a geographic survey on the counter service establishments in Pavia, Northern Italy, analyze their characteristics, create a map of their distribution in the various areas of the town and investigate the increase in their presence compared with past years.

\section{Methods}

This observational study was carried out in Pavia, Northern Italy. The location, kind and distribution within the town of counter service establishments were investigated by means of a street survey, exploring the town areas to determine these locations. The survey was conducted on feet over a two-week period, from May $14^{\text {th }}$ until May $31^{\text {st }} 2012$

A map of the town was divided into six different areas (Figure 1 ), and the geographic survey was conducted exploring area by area, starting from the suburbs and ending up in the town center.

Area number five is the centre area, while numbers one to four and number six are the suburbs areas. It took four days, eight hours a day, to investigate each area.

Data were collected using a standardized form concerning the kind, location and area of each counter service establishment. The different types of locations were drawn on the town map in order to point out the major concentration of them in the various areas of the town.

Data were finally compared with those provided by the Commercial Agency of Pavia for 2002, since they are the most recent ones, to evaluate how the presence and the distribution of counter service establishments had changed.
Data were processed using the Statistical Package for the Social Sciences version 18 for PC (SPSS Inc., Chicago, IL, USA) and expressed as percentage (\%) among all the counter service establishments.

Ethical approval as well as review by the institutional review board were not required for this study because human subjects were not involved.

\section{Classification of Counter Service Establishments}

Counter service establishments were divided into five different categories, on the basis of the Region Lombardy Guidelines [16], according to the different nutritional strategy for customer care: bar, self-service, pizzeria, kebab shop and takeaway.

In particular:

- a bar is a quick service food establishment (furnished or fitted with tables, counters, chairs, benches or like facilities designed or adapted for use in consuming food) where meals, made-to-order sandwiches, light refreshments and alcoholic and non-alcoholic beverages are prepared, served to customers and consumed on the premises;

- a self-service is a food establishment (furnished or fitted with tables, counters, chairs, benches or like facilities designed or adapted for use in consuming food) where a wide selection of foods primarily typical of the Italian diet are prepared in a dedicate kitchen and the customer serves himself for consumption on the premises; alcoholic and non-alcoholic beverages are also available for consumption;

- a pizzeria is a food establishment (furnished or fitted with

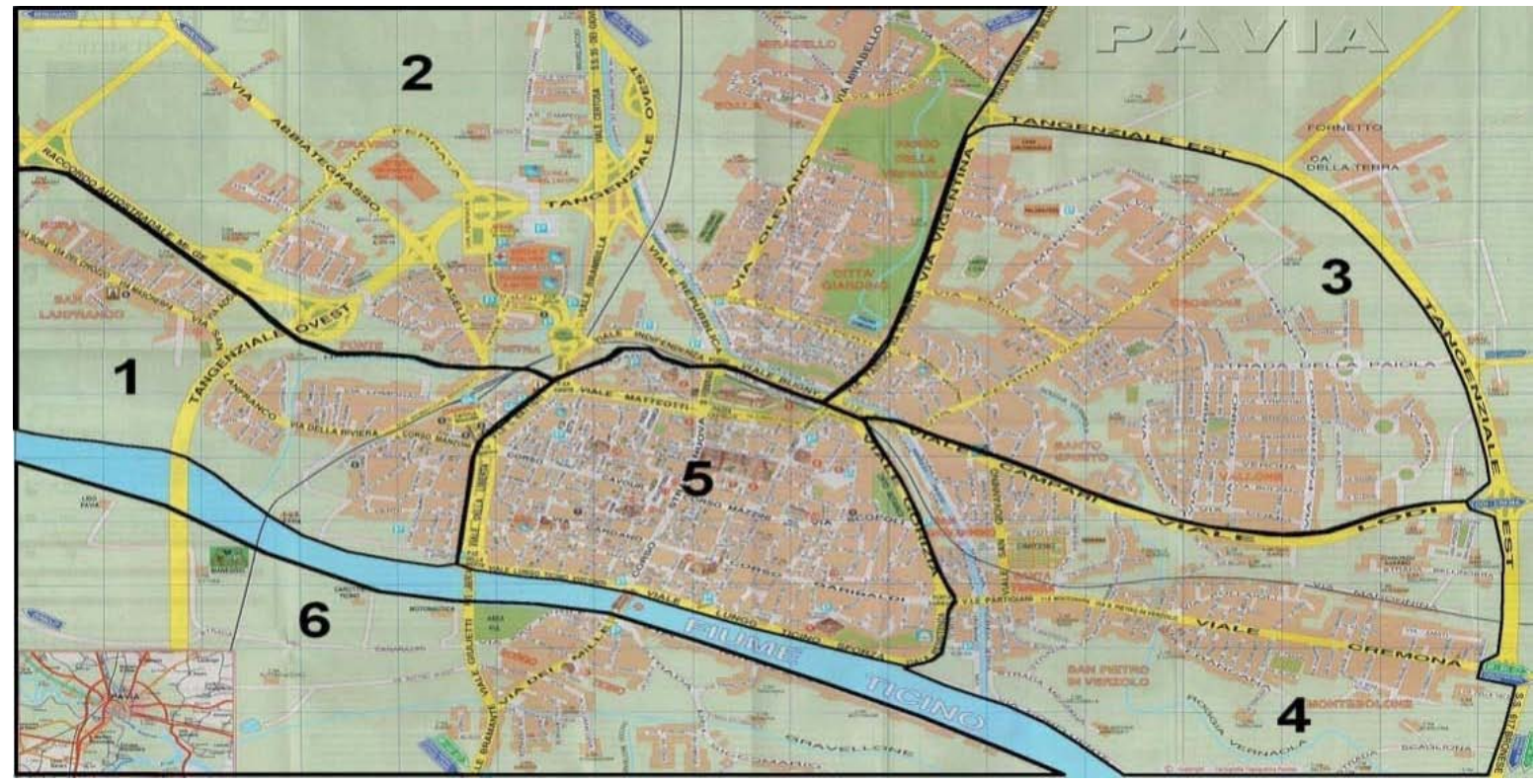

Figure 1: Map of the town divided into six different areas. 
tables, counters, chairs, benches or like facilities designed or adapted for use in consuming food) where "pizzas" are prepared, served to customers and consumed on the premises; alcoholic and non-alcoholic beverages are also available for consumption;

- a kebab shop is a quick service food establishment (not furnished or fitted with tables, counters, chairs, benches or like facilities designed or adapted for use in consuming food) where traditional Middle East meals and non-alcoholic beverages are prepared and sold for consumption off the premises;

- a take-away is a quick service food establishment (not furnished or fitted with tables, counters, chairs, benches or like facilities designed or adapted for use in consuming food) where meals, light refreshments are prepared in a dedicate kitchen and sold for consumption off the premises.

Traditional full-service restaurants were not here included because they do not fall within the counter service category.

\section{Results}

Table 1 shows the comparison between counter service establishments in 2002 and 2012 and Table 2 reports their actual distribution in the various areas in Pavia. Two hundred and thirty establishments were found in 2012, showing an increase of them when compared with 2002. Figure 2 shows the distribution of counter service establishments on Pavia map.

Data analysis shows that the bar is the most represented category, with 160 locations (69.6\%), followed by pizzeria $(\mathrm{n}=$
$35,15.2 \%)$, take-away $(\mathrm{n}=23,10.0 \%)$ and self-service and kebab shop $(n=6,2.6 \%)$ to the same extent.

The establishments are most widespread in the center area (number five). The distribution of locations in this area reflects the general distribution in the town, where the bar is the most represented category, accounting for 70 of the 93 (75.3\%) surveyed overall.

The town area in which establishments are least represented is number four, corresponding to the Northern-Eastern suburbs, where 14 of the 230 locations are situated.

Comparing our data with those collected in 2002, provided by the Commercial Agency of Pavia, the percentage of take-aways and kebab shops amongst all the establishments increased from $1.6 \%$ to $12.6 \%$

\section{Discussion}

Our study carried out a geographic survey on the counter service establishments in Pavia, Northern Italy, analyzed their characteristics, produced a map of their distribution in the various areas of the town and investigated the increase in their presence compared with past years. The bar is the most represented type of establishment and the various types of locations are situated primarily in the central business, commercial and cultural district of the town. The percentage of take-aways and kebab shops amongst all the establishments increased from $1.6 \%$ in 2002 to $12.6 \%$ in 2012.

The counter service establishments offer new, cheaper foods and globalize the dietary habits of Italian people, and may promote negative influence on the Italian cooking tradition by

Table 1: Comparison between counter service establishments in years 2002 and in 2012.

\begin{tabular}{|c|c|c|c|c|c|}
\hline \multirow[t]{2}{*}{ Establishments } & \multicolumn{2}{|c|}{2002 (n of people 71,214 ) } & \multicolumn{2}{|c|}{2012 (n of people 68,280 ) } & \multirow{2}{*}{$\begin{array}{c}2002-2012 \\
\Delta \%\end{array}$} \\
\hline & $\mathbf{n}$ & $\%$ & $\mathbf{n}$ & $\%$ & \\
\hline Bar & 148 & 80.4 & 160 & 69.6 & -10.8 \\
\hline Self-service & 3 & 1.6 & 6 & 2.6 & +1.0 \\
\hline Pizzeria & 30 & 16.4 & 35 & 15.2 & -1.2 \\
\hline Kebab shop & 0 & 0 & 6 & 2.6 & +2.6 \\
\hline Take away & 3 & 1.6 & 23 & 10.0 & +8.4 \\
\hline Total & 184 & 100 & 230 & 100 & \\
\hline
\end{tabular}

Table 2: Counter service establishments distribution in the various areas in Pavia.

\begin{tabular}{|c|c|c|c|c|c|c|}
\hline Town area & Bar & Self-service & Pizzeria & Kebab shop & Take-away & Total \\
\hline Area 1 & 29 & 0 & 7 & 1 & 1 & $38(16.5 \%)^{*}$ \\
\hline Area 2 & 29 & 1 & 6 & 1 & 3 & $40(17.4 \%)^{*}$ \\
\hline Area 3 & 13 & 3 & 5 & 0 & 5 & $26(11.3 \%)^{*}$ \\
\hline Area 4 & 8 & 0 & 3 & 0 & 3 & $14(6.1 \%)^{*}$ \\
\hline Area 5 & 70 & 0 & 11 & 3 & 9 & $93(40.4 \%)^{*}$ \\
\hline Area 6 & 11 & 2 & 3 & 1 & 2 & $19(8.3 \%)^{*}$ \\
\hline Total number of establishments & 160 & 6 & 35 & 6 & 23 & 230 \\
\hline
\end{tabular}

$*_{\text {in brackets percentage of establishments }}$ 
contributing to the decline of the traditional Mediterranean diet in favor of an unhealthy as well as unbalanced diet.

The Mediterranean diet is characterized by a high intake of vegetables, legumes, fruits and cereals (that in the past were largely unrefined), and a high intake of extra-virgin olive oil but a low intake of saturated fatty acids, a moderately high intake of fish (depending on the proximity of the sea), a low-to-moderate intake of dairy products (mostly in the form of cheese or yogurt), a low intake of meat and poultry, and a moderate intake of wine, specially the red one, drunk during meals[17].

Indeed, a typical characteristic of the Mediterranean habits, which are in line with the dietary guidelines for a healthy diet, is the tendency to attribute values to the diet that go beyond the merely nutritional or functional aspect, by considering the pleasures of the table as well [3] Currently, in Mediterranean countries, due to socio-economic factors, there is a tendency for traditional living and eating styles to be lost, leaving the way open to habits, styles and ways of consuming food typical of other traditions, which are often poor in nutritional content and do not consider dietary aspects of social relations and significance $[3,15,17,18]$.

In recent decades, these changes have occurred in Italy as well, and have negatively influenced the Mediterranean characteristics of the diet of Italian people who, due to social, professional or economic difficulties, have often modified where and how they eat throughout the day [3].

The situation in Pavia reflects this tendency. Indeed, as demonstrated by our results, the last decade has seen increasing

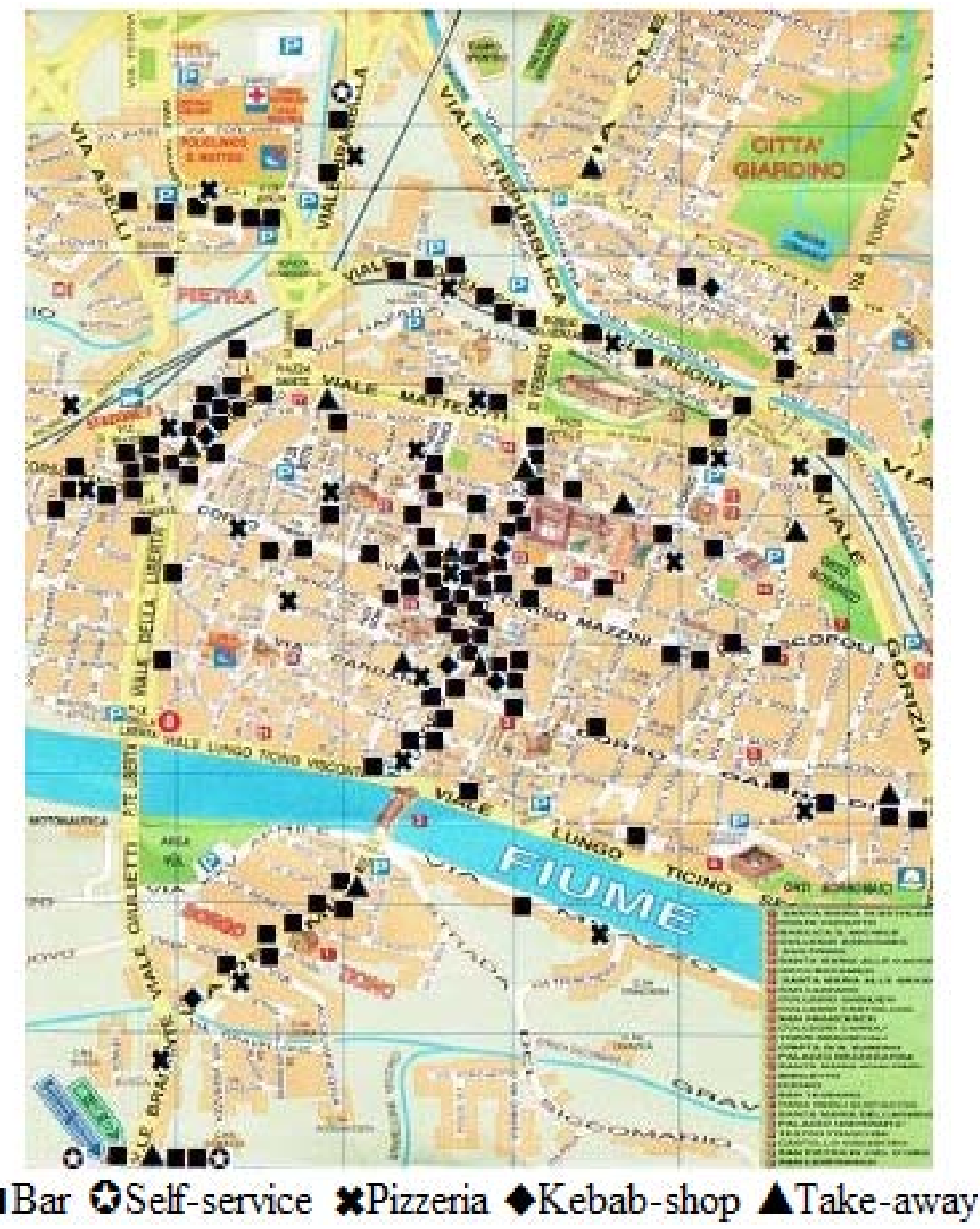

Figure 2: Distribution of counter service establishments in Pavia in 2012. 
growth in take-aways and kebab shops as a consequence of the high demand of fast food. In addition, the need for short lunch breaks near the workplace produces the highest distribution of bars, pizzerias, take-aways and kebab shops especially in the town center area where most of the offices, schools and university departments are located: most of the counter service establishments surveyed $(n=93,40.4 \%)$ were in this area.

On the other hand, self-service outlets that also offer fast food more representative of the Mediterranean diet are located in the suburbs, especially in shopping centers, where many people from the surrounding area come for shopping during the weekend.

Modern sedentary lifestyle and the increasing consumption of unhealthy foods have contributed to the increased prevalence rate of obesity in our country too, and changes in dietary habits, together with a sedentary lifestyle, are the leading cause of this disease [19]. Considering the high costs associated with obesity and other correlated diseases, improving healthy dietary habits should be the primary goal of the public health institutions. This goal might be reached through promoting and selecting those foods offered by the local supply and cultural traditions of the region.

The Mediterranean diet, besides being a set of traditional practices, knowledge and skills passed on from generation to generation and providing a sense of belonging and continuity to the communities in question, is also considered an optimal diet from a health perspective, because it provides scientifically proven health benefits and counteracts the taste preference for so-called "junk food" [20-24]. Indeed, on November $16^{\text {th }} 2010$ it was inscribed by UNESCO on the Representative List of the Intangible Cultural Heritage of Humanity [25].

A recent meta-analysis on more than 1.5 million persons shows that adherence to the Mediterranean diet can significantly decrease the risk of overall mortality, mortality from cardiovascular diseases, incidence of or mortality from cancer, and incidence of Parkinson's as well as Alzheimer's diseases[26]. These results seem to be clinically relevant in terms of public health, particularly for reducing the risk of premature death in the general population.

Our study has a few limitations that must be considered. First, we used two different methods of survey in the two years investigated since the Commercial Agency of Pavia data for 2012 were not available and this could be a bias. Another limitation of our study is that we did not investigate the nutritional characteristics and the frequency of consumption of the foods eaten in these establishments nevertheless the study itself raises the important problem of the adhesion to Mediterranean diet of Italian people. Finally, we surveyed the presence of the counter service establishments in Pavia, but we did not evaluate the demand and the actual flow of people and this limitation of our study could serve as inspiration for future research.

In our modern society, many people follow unhealthy dietary habits and unbalanced diet, potentially contributing to the onset of degenerative chronic diseases. Therefore, public nutrition policy makers should focus their attention on providing knowledge, particularly to young people, in order to improve dietary habits, to help people to adopt a balanced healthy diet as well as active lifestyle as a constant habit throughout life, and to promote awareness in the population about the relationship between nutrition and health, thus helping to develop a healthy food culture [24].

\section{Conflict of Interests}

There are no financial or other contractual agreements that might cause conflicts of interest.

\section{References}

1. ISTAT. Indagine campionaria Famiglia e soggetti sociali. Come cambiano le forme familiari. Report. 2011.

2. ISMEA. Consumi Extra Domestici dei prodotti alimentari: Indagine qualitativa II semestre 2006. Roma; 2007.

3. BCFN. Il valore della Mediterraneità. Position Paper; 2010.

4. Nielsen Italia

5. Fondazione Ismu. Diciassettesimo Rapporto sulle migrazioni 2011. Iniziative e Studi sulla Multietnicità. Collana ISMU, Franco Angeli ed. Milano; 2012.

6. ISTAT. Gli indici dei prezzi al consumo. Nota informativa; 2011.

7. Parente G. Cibo veloce e cibo di strada. Le tradizioni artigianali del fastfood in Italia alla prova della globalizzazione, 2007.

8. Epicentro.Il portale dell'epidemiologia per la sanità pubblica.

9. Baldini M, Pasqui F, Bordoni A, Maranesi M. Is the Mediterranean lifestyle still a reality? Evaluation of food consumption and energy expenditure in Italian and Spanish university students. Public Health Nutr. 2009; 12(2): 148-55. doi: 10.1017/S1368980008002759.

10. Garcia G, Sunil TS, Hinojosa P. The fast food and obesity link: consumption patterns and severity of obesity. Obes Surg. 2012; 22(5): 810-18. doi: 10.1007/s11695-012-0601-8.

11. Lamberti A, Baglio G, Nardone P. OKkio alla SALUTE: Il problema dell'obesità infantile e dei fattori di rischio comportamentali-risultati, 2010.

12. Panico S, Palmieri L, Donfrancesco C, et al. Il potenziale preventivo della riduzione dell'indice di massa corporea per ridurre il rischio cardiovascolare: il Progetto CUORE. G Ital Cardiol (Roma). 2010; 11(5 Suppl 3):43S-47S.

13. Vanuzzo D, Lo Noce C, Pilotto L, et al. Osservatorio Epidemiologico Cardiovascolare 2008-2011: primi risultati. G Ital Cardiol (Roma). 2010; 11(5 Suppl 3): 25S-30S.

14. Donfrancesco C, Palmieri L, Vannucchi S, et al. Cnesps-Iss. Salute cardiovascolare delis italiani: i dati preliminari dell'indagine Oec/Hes 2008; 12.2012.

15. Schmidhuber J. The EU Diet - Evolution, Evaluation and Impacts of the CAP. Paper by presented at the WHO Forum on "Trade and healthy food and diets", Montreal. 2007.

16. Decreto della Giunta Regionale Lombarda n.6459/2008.

17. Trichopoulou A, Costacou T, Christina B, Trichopoulos D. Adherence to a Mediterranean diet and survival in a Greek population. N Engl J Med. 2003; 348(26): 2599-608. 
18. Alexandratos N. The Mediterranean diet in a world context. Public Health Nutr. 2006; 9 (1A): 111-7

19. Rosenheck R. Fast food consumption and increased caloric intake: a systematic review of a trajectory towards weight gain and obesity risk. Obes Rev. 2008; 9(6): 535-47. doi: 10.1111/j.1467789X.2008.00477.x.

20. Sofi F. The Mediterranean diet revisited: evidence of its effectiveness grows. Curr Opin Cardiol. 2009; 24(5): 442- 6. doi: 10.1097/ HCO.0b013e32832f056e.

21. Sofi F, Abbate R, Gensini GF, Casini A. Which diet for an effective cardiovascular prevention? Monaldi Arch Chest Dis. 2012; 78(2): 605

22. Misirli G, Benetou V, Lagiou P, Bamia C, Trichopoulos D, Trichopoulou A. Relation of the Traditional Mediterranean Diet to Cerebrovascular
Disease in a Mediterranean Population. Am J Epidemiol. 2012; 176(12): 1185-92. doi: 10.1093/aje/kws205.

23. Di Daniele N, Petramala L, Di Renzo L, Sarlo F, Della Rocca DG, Rizzo $\mathrm{M}$, et al. Body composition changes and cardiometabolic benefits of a balanced Italian Mediterranean Diet in obese patients with metabolic syndrome. Acta Diabetol. 2013; 50(3): 409-16. doi: 10.1007/s00592012-0445-7.

24. Bifulco M, Caruso MG. From the Gastronomic Revolution to the New Globesity Epidemic. J Am Diet Assoc. 2007; 107 (12): 2058-60.

25. UNESCO. United Nations Educational, Scientific and Cultural Organization.

26. Sofi F, Cesari F, Abbate R, Gensini GF, Casini A. Adherence to Mediterranean diet and health status: meta-analysis. BMJ. 2008; 337: a1344. doi: 10.1136/bmj.a1344. 